\title{
SYNTHESIS AND ANALYSIS OF DATA ON THE JACKSON ELK HERD
}

\author{
Mark S. Boyce \\ Department of Zoology and Physiology \\ University of Wyoming \\ Laramie
}

\section{Objectives}

The principal objective of this research is to compile, synthesize, and evaluate available data on the ecology and management of the Jackson elk herd. When the analysis has been completed, I will offer my interpretation of management implications that may be deduced from these data, and offer directions for future research to best enhance management for the elk herd. Initiative and funding for this research came from the Jackson Hole Cooperative Elk Studies Group, which determines management direction for the Jackson elk herd.

\section{Methods}

This study does not entail field work or collection of new data, but involves a compilation and analysis of existing information. Considerable data relating to the ecology and management of the Jackson elk herd exist in files and reports of the 4 agencies responsible for its management, i.e., the Wyoming Game and Fish Department; U.S. National Park Service, Grand Teton National Park; U.S. Fish and Wildlife Service, National Elk Refuge; and U.S. Forest Service, Bridger-Teton National Forest. During the spring and summer of 1985 I visited offices of these agencies and compiled data relevant for my analysis. Activities this fall and winter have focused on organization and statistical analysis of these data.

\section{Results}

Extensive data on the Jackson elk herd have been collected annually since the establishment of the National Elk Refuge in 1912, generating a nearly overwhelming quantity of information. To mention but a portion of the data base, some of the information that I have been studying includes (1) details of hunter harvest over a large number of years as determined by check stations and mail surveys, (2) track counts of elk migrating across road transects during autumn and early winter, (3) annual counts of elk classified by sex and age on the National Elk Refuge and Gros Ventre feedgrounds, (4) mortality of elk on the National Elk Refuge, (5) quantities of feed provided for elk on the National Elk Refuge, (6) ear tag recoveries of elk marked from the Jackson elk herd and surrounding herds, (7) trend counts of elk summering in Grand Teton National Park, and (8) land-use changes in the Teton valley including road construction, development, livestock grazing and timbering. 
A major direction for my analysis of this large data set has been to condense complex patterns into formats that are readily interpretable and therefore of greater value for management. For example, the track count data include tens of thousands of observations which vary spatially, within and among years, and possess covariance with several independent variables, including hunter harvest and snowfall. Comprehending such an enormous body of information requires distillation into a few key parameters of interest. My approach here has been to employ multivariate procedures, including multidimensional scaling, multiple regression, principal components analysis, and canonical correlation.

'The objective behind this multivariate statistical analysis is actually to simplify, rather than to complicate the interpretation of the results. For example, my analysis of track counts suggests that snowfall plays a major role determining not only the timing of migration from summer to winter ranges, but also the relative fraction of elk using various migration routes. During mild autumns, a greater proportion of elk migrate across transects within Grand Teton National Park, whereas heavy snowfall appears to force more elk to migrate across Highway 26/287 east of the Park. Another major factor determining migration patterns is the spatial distribution of hunter harvest during previous years. These patterns are certainly not transparent from the original data, but multivariate analysis permits an interpretable summary of numerous interacting variables.

\section{Conclusions}

Since data analysis is still in progress, it is inappropriate to suggest conclusions at this time. Many of the suggestions of Anderson (1958) and Cole (1969) regarding population ecology of the Jackson elk herd appear to be supported by statistical analysis of data. However, since those early studies numerous changes have occurred in the population structure, migration pattern and distribution of elk in Jackson Hole. Scheduled completion for this project is I July 1986.

\section{Literature Cited}

Anderson, C. C. 1958. The elk of Jackson Hole: A review of Jackson elk studies. Bull No. 10. WY Game and Fish Comm., Cheyenne.

Cole, G. F. 1969. The elk of Grand Teton and southern Yellowstone National Parks. Res. Rept. GRTE-N-1, Office of Nat. Sci. Studies, Nat'l Park Serv., Wash., DC. 